\title{
Application of Improved PID Controller in Motor Drive System
}

\author{
Song Shoujun and Liu Weiguo \\ Northwestern Polytechnical University \\ China
}

\section{Introduction}

PID (proportional-integral-derivative) controller has being widely used in motor drive system. More than $90 \%$ of industrial controllers are implemented based on PID algorithms (Ang et al., 2005). The structure of PID controller is very simple and its control principle is very clear. It is practical and is very easy to be implemented. What's more, because the functionalities of the three factors in PID controller are very clear, they can be tuned efficiently to obtain desired transient and steady-state responses.

Motor drive systems can be found in many applications, their behaviours can influence the performances of the whole system tremendously. The motor drive system has many distinct features, such as multivariable, strong nonlinearity and strong coupling (Li et al., 2010). Many parameters in the system are time-variant. What's more, in many cases, it's very difficult to get the accurate mathematical model of the motor drive system. All these features make the control of the motor drive system difficult.

PID controller is very popular in the control of the motor drive system. However, since the controller parameters are fixed during control after they have been chosen through a certain optimal method, the conventional PID controller can't always keep satisfying performances. To cope with this problem, the parameters of the controller need to be adjusted dynamically according to the running status of the system. Many on-line tuning algorithms, such as fuzzy logic, neural network and genetic algorithm, have been introduced into PID controller to achieve desired control performances for the entire operating envelope of the motor drive system (Tang et al., 2001; Yu et al., 2009; Lin et al., 2003).

In this chapter, two improved self-tuning PID controllers are given and studied in detail. To verify their validity, two typical motor drive systems, namely switched reluctance motor (SRM) drive system (Chen \& Gu, 2010) and brushless DC motor (BLDCM) drive system (Wu et al., 2005), are introduced as examples. Based on the models of these two drive systems, the performances of the improved PID controllers are analyzed in detail.

\section{Conventional PID Controller}

In analog control system, PID controller is used commonly. The conventional PID (C-PID) controller is a linear control method. It compounds the outputs of proportional, integral and 
derivative parts linearly to control the system. Fig. 1 shows the block diagram of the C-PID controller.

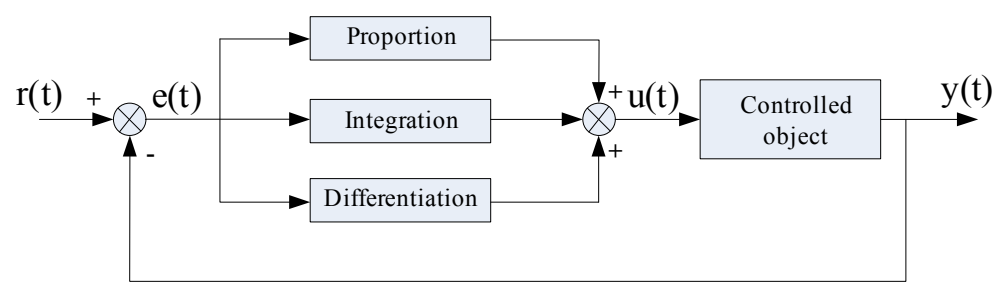

Fig. 1. Block diagram of the C-PID controller

The algorithm of C-PID controller can be given as follows:

$$
\begin{gathered}
e(t)=r(t)-y(t) \\
u(t)=K_{p}\left[e(t)+\frac{1}{T_{i}} \int e(t) d t+T_{d} \frac{d e(t)}{d t}\right]
\end{gathered}
$$

where $y(t)$ is the output of the system, $r(t)$ is the reference input of the system, $e(t)$ is the error signal between $y(t)$ and $r(t), u(t)$ is the output of the C-PID controller, $K_{p}$ is proportional gain, $T_{i}$ is integral time constant and $T_{d}$ is derivative time constant.

Equation (2) also can be rewritten as (3):

$$
u(t)=K_{p} e(t)+K_{i} \int e(t) d t+K_{d} \frac{d e(t)}{d t}
$$

where $K_{i}$ is integral gain, $K_{d}$ is derivative gain, and $K_{i}=K_{p} / T_{i}, K_{d}=K_{p} T_{d}$.

In C-PID controller, the relation between PID parameters and the system response specifications is clear. Each part has its certain function as follows (Shi \& Hao, 2008):

(1) Proportion can increase the response speed and control accuracy of the system. Bigger $K_{p}$ can lead to faster response speed and higher control accuracy. But if $K_{p}$ is too big, the overshoot will be large and the system will tend to be instable. Meanwhile, if $K_{p}$ is too small, the control accuracy will be decreased and the regulating time will be prolonged. The static and dynamic performance will be deteriorated.

(2) Integration is used to eliminate the steady-state error of the system. With bigger $K_{i}$, the steady-state error can be eliminated faster. But if $K_{i}$ is too big, there will be integral saturation at the beginning of the control process and the overshoot will be large. On the other hand, if $K_{i}$ is too small, the steady-state error will be very difficult to be eliminated and the control accuracy will be bad.

(3) Differentiation can improve the dynamic performance of the system. It can inhibit and predict the change of the error in any direction. But if $K_{d}$ is too big, the response process will brake early, the regulating time will be prolonged and the anti-interference capability of the system will be bad. 
The three gains of C-PID controller, $K_{p}, K_{i}$ and $K_{d}$, can be determined conveniently according to the above mentioned function of each part. There are many methods such as NCD (Wei, 2004; Qin et al., 2005) and genetic algorithm can be used to determine the gains effectively.

(1) NCD is a toolbox in Matlab. It is developed for the design of nonlinear system controller. On the basis of graphical interfaces, it integrates the functions of optimization and simulation for nonlinear system controller in Simulink mode.

(2) Genetic algorithm (GA) is a stochastic optimization algorithm modeled on the principles and concepts of natural selection and evolution. It has outstanding abilities for solving multi-objective optimization problems and finding global optimal solutions. GA can readily handle discontinuous and nondifferentiable functions. In addition, it is easily programmed and conveniently implemented (Naayagi \& Kamaraj, 2005; Vasconcelos et al., 2001).

In many conventional applications, the gains of C-PID controller are determined offline by one of the methods mentioned above and then fixed during the whole control process. This control scheme has two obvious shortcomings as follows:

(1) All the methods that can be used to determine the gains of C-PID controller offline are based on the precise mathematical model of the controlled system. However, in many applications, such as motor drive system, it is very difficult to build the precise mathematical model due to the multivariable, time-variant, strong nonlinearity and strong coupling of the real plant.

(2) In many applications, some parameters of the controlled system are not constant. They will be changed according to different operation conditions. For example, in motor drive system, the winding resistance of the motor will be changed nonlinearly along with the temperature. If the gains of C-PID controller are still fixed, the performance of the system will deteriorate.

To overcome these disadvantages, C-PID should be improved. The gains of PID controller should be adjusted dynamically during the control process.

\section{Improved PID Controller}

There are many techniques such as fuzzy logic control, neural network and expert control (Xu et al., 2004) can be adopted to adjust the gains online according to different conditions. In this chapter, two kinds of Improved PID (I-PID) controller based on fuzzy logic control and neural network are studied in detail.

\subsection{Fuzzy Self-tuning PID Controller}

Fuzzy logic control (FLC) is a typical intelligent control method which has been widely used in many fields, such as steelmaking, chemical industry, household appliances and social sciences. The biggest feature of FLC is it can express empirical knowledge of the experts by inference rules. It does not need the mathematical model of the controlled object. What's more, it is not sensitive to parameters changing and it has strong robustness. In summary, FLC is very suitable for the controlled object with characteristics of large delay, large inertia, non-linear and time-variant (Liu \& Li, 2010; Liu \& Song, 2006; Shi \& Hao, 2008).

The structure of a SISO (single input single output) FLC is shown in Fig. 2. It can be found that the typical FLC consists of there main parts as follows: 


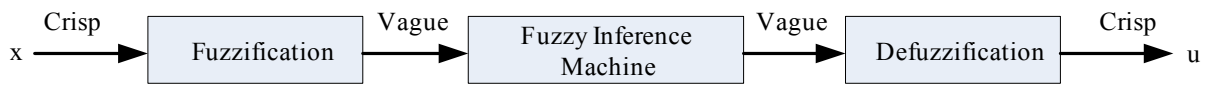

Fig. 2. The structure of SISO FLC

(1) Fuzzification comprises the process of transforming crisp inputs into grades of membership for linguistic terms of fuzzy sets. The input values of a FLC consist of measured values from the plant that are either plant output values or plant states, or control errors derived from the set-point values and the controlled variables.

(2) Fuzzy Inference Machine is the core of a fuzzy control system. It combines the facts obtained from the fuzzification with the rule base and conducts the fuzzy reasoning process. A proper rule base can be found either by asking experts or by evaluation of measurement data using data mining methods.

(3) Defuzzification transforms an output fuzzy set back to a crisp value. Many methods can be used for defuzzification, such as centre of gravity method (COG), centre of singleton method (COS) and maximum methods.

Detailed analyses show that FLC is a nonlinear PD controller. It cannot eliminate steadystate error when the controlled object does not have integral element, so it is a ragged controller. To overcome this disadvantage, FLC is often used together with other controllers. Fig. 3 shows the structure of a controller called Fuzzy_PID compound controller. When the error is big, FLC is used to accelerate the dynamic response, and when the error is small, PID controller is used to enhance the steady-state accuracy of the system (Liu \& Song, 2006).

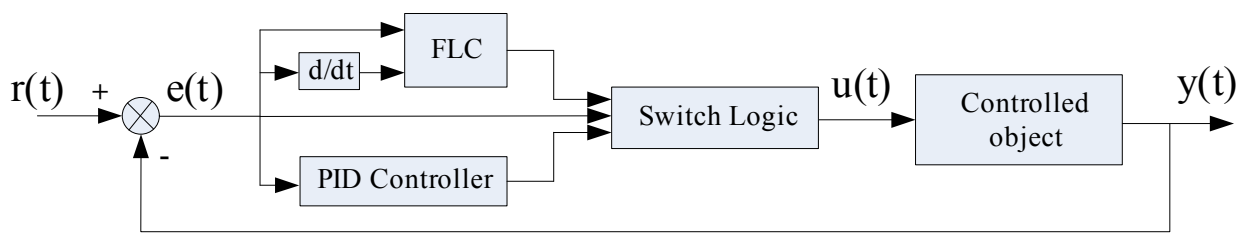

Fig. 3. The structure of Fuzzy_PID compound controller

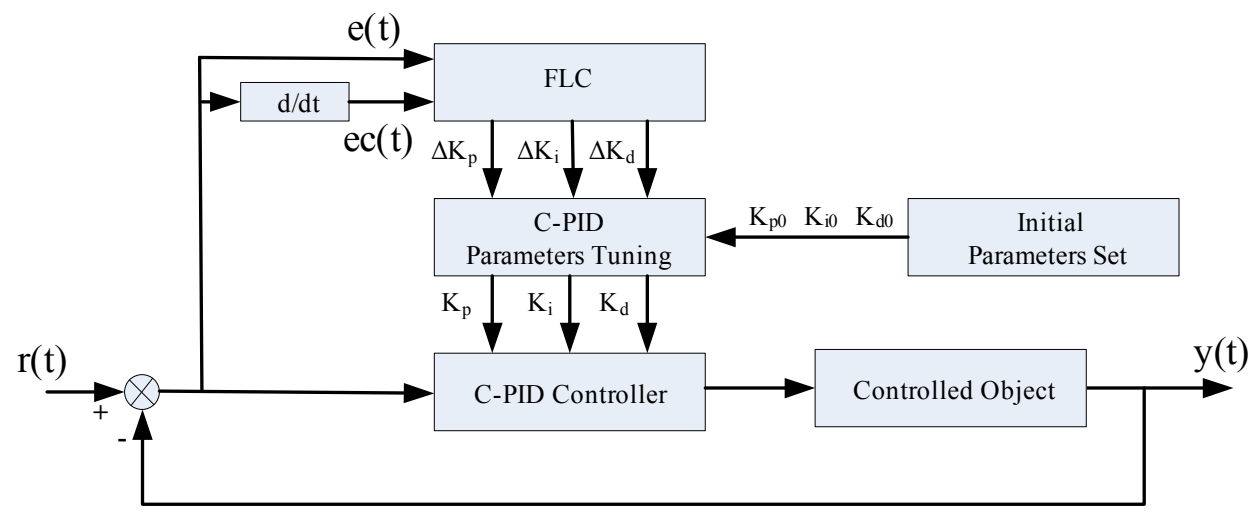

Fig. 4. The structure of FPID controller 
In this chapter, an I-PID controller called fuzzy self-tuning PID (FPID) controller is introduced. In this controller, FLC is used to tune the parameters of C-PID controller online according to different conditions. Fig. 4 shows the structure of FPID controller (Liu \& $\mathrm{Li}$, 2010).

In FPID controller, the error signal and the rate of change of error are inputted into FLC firstly. After fuzzy inference based on the rule base, the increments of PID control parameters, $\Delta \mathrm{K}_{\mathrm{p}}, \Delta \mathrm{K}_{\mathrm{i}}$ and $\Delta \mathrm{K}_{\mathrm{d}}$, are obtained, add these increments to initial values of PID control parameters, the actual PID control parameters can be achieved finally. The initial values of PID control parameters, $\mathrm{K}_{\mathrm{p} 0}, \mathrm{~K}_{\mathrm{i} 0}$ and $\mathrm{K}_{\mathrm{d} 0}$, can be obtained by the methods mentioned in the last section.

\subsection{Neural Network PID Controller}

Neural network $(\mathrm{NN})$ is a mathematical model or computational model inspired by the structure and functional aspects of biological neural systems, such as the brain. It is composed of a large number of highly interconnected processing elements (neurones) working in unison to solve specific problems. Fig. 5 shows the typical structure of a NN. It has one input layer, one output layer and several hidden layers. In each layer, there are a certain number of nodes (neurons). The neurons in adjacent layers are connected together, while there are no connections between neurons in the same layer. Just like the biological neural systems, the NN also can learn by itself. During the learning phase, the connection strength (weights) between neurons can be adjusted by certain algorithms automatically based on external or internal information that flows through the network. (Tao, 2002; Liu, 2003; Wang et al., 2007)

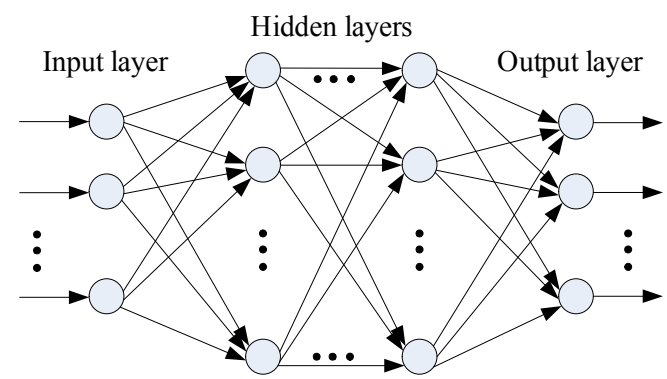

Fig. 5. The structure of a typical NN

The greatest advantage of $\mathrm{NN}$ is its ability to be used as an arbitrary function approximation mechanism which 'learns' from observed data. There are many other remarkable advantages of NN as follows:

(1) Adaptive learning: An ability to learn how to do tasks based on the data given for training or initial experience.

(2) Real time operation: NN can process massive data and information in parallel. Special hardware devices are being designed and manufactured which take advantage of this capability.

(3) Fault tolerance: Some capabilities of NN can be retained even with major network damage. 
BP (backpropagation) neural network (BPNN) is the most popular neural network for practical applications. It adopts the backpropagation learning algorithm which can be divided into two phases: data feedforward and error backpropagation.

(1) Data feedforward: In this phase, the data, such as the error of the controlled system, inputted into the input layer is fed into the hidden layer and then into the output layer. Finally, the output of the BPNN can be obtained from the output layer. It is the function of the connection weights between neurons.

(2) Error backpropagation: In this phase, the actual output value of the network obtained in the last phase is compared with a desired value. The error between them is propagated backward. The connection weights between neurons are adjusted by some means, such as gradient descent algorithm, based on the error.

These two phases are repeated continuously until the performance of the network is good enough.

In this chapter, BPNN is used to tune the parameters of C-PID controller online. Fig. 6 shows the structure of this I-PID controller named NNPID controller.

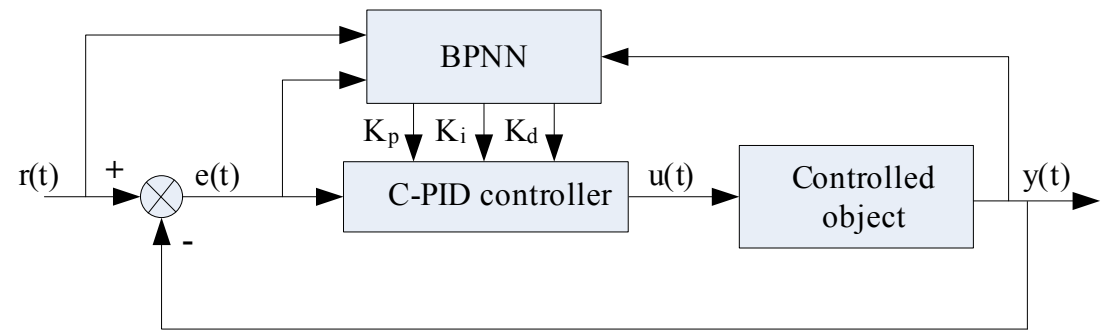

Fig. 6. The structure of NNPID controller

It can be seen that NNPID controller consists of C-PID controller and BPNN. C-PID controller is used to control the plant directly. Its output, $u(t)$, can be obtained by (3). In order to optimize the performance of the system, BPNN is used to adjust the three parameters of C-PID controller online based on some state variables of the system.

\section{Motor Drive System}

Motor is the main controlled object in motor drive system. In practical applications, there are many kinds of motors. In this chapter, the brushless DC motor (BLDCM) and switched reluctance motor (SRM) are studied as examples. Their mathematical models are built to simulate the performance of different control methods.

\subsection{Brushless DC Motor}

In BLDCM, electronic commutating device is used instead of the mechanical commutating device. Because BLDCM has many remarkable advantages, such as high efficiency, silent operation, high power density, low maintenance, high reliability and so on, it has been widely used in many industrial and domestic applications. 
The voltage equation for one phase in BLDCM can be written as:

$$
u=e+i_{a} R_{a}+L_{a} \frac{d i_{a}}{d t}
$$

where $u, i_{a}, R_{a}$ and $L_{a}$ are the voltage, current, resistance and inductance of one phase, respectively. $e$ is the back EMF (electromotive force) which can be calculated by

$$
e=C_{e} \Phi n=k_{v} \omega
$$

where $\omega$ is the angular speed of the rotor, $k_{v}$ is a constant which can be calculated by

$$
k_{v}=\frac{30}{\pi} C_{e} \Phi=9.55 C_{e} \Phi
$$

where $C_{e}$ is the EMF constant and $\Phi$ is the flux per pole.

The torque equation can be given as

$$
T_{e m}=T_{L}+B \omega+J \frac{d \omega}{d t}
$$

where $T_{e m}$ is electromagnetic torque, $T_{L}$ is load torque, $B$ is damping coefficient and $J$ is rotary inertia.

$T_{e m}$ also can be obtained by

$$
T_{e m}=C_{T} \Phi i_{a}=k_{t} i_{a}
$$

where $k_{t}$ is a constant which can be calculated by

$$
k_{t}=C_{T} \Phi
$$

where $C_{T}$ is the torque constant.

Based on all above equations, the state space equation of BLDCM can be obtained as

$$
\frac{d}{d t}\left[\begin{array}{c}
i_{a} \\
\omega
\end{array}\right]=\left[\begin{array}{cc}
-\frac{R_{a}}{L_{a}} & -\frac{k_{v}}{L_{a}} \\
\frac{k_{t}}{J} & -\frac{B}{J}
\end{array}\right]\left[\begin{array}{c}
i_{a} \\
\omega
\end{array}\right]+\left[\begin{array}{cc}
\frac{1}{L_{a}} & 0 \\
0 & -\frac{1}{J}
\end{array}\right]\left[\begin{array}{c}
u \\
T_{L}
\end{array}\right]
$$

The Laplace transform of (10) can be written as two equations as follows:

$$
\left\{\begin{array}{l}
I_{a}(s)=\frac{-k_{v} \omega(s)+U(s)}{L_{a} s+R_{a}} \\
\omega(s)=\frac{k_{t} I_{a}(s)-T_{L}}{J_{s}+B}
\end{array}\right.
$$


According to (11), the simulation model of BLDCM can be built in Matlab/simulink as shown in Fig. 7.

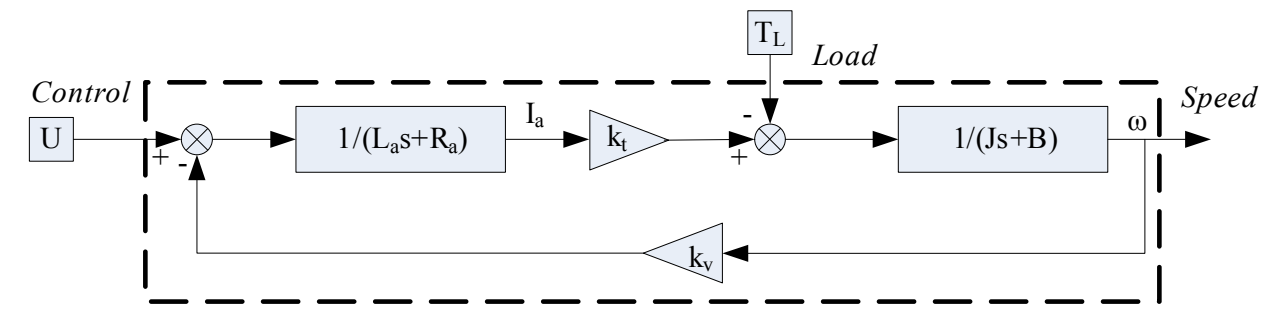

Fig. 7. The simulation model of BLDCM

\subsection{Switched Reluctance Motor}

The SRM is a brushless synchronous machine with salient rotor and stator teeth. There are concentrated phase windings in the stator, and no magnets and windings in the rotor. It has many remarkable advantages such as simple magnetless and rugged construction, simple control, ability of extremely high speed operation, relatively wide constant power capability, minimal effects of temperature variations offset, low manufacturing cost and ability of hazard-free operation. These advantages make the SRM very suitable for applications in more/all electric aircraft (M/A EA), electric vehicle (EV) and wind power generation.

Because the nonlinear model of SRM is very complex, people generally use its quasi-linear model to design and analyze control methods.

According to the quasi-linear model of SRM, the average torque equation can be obtained as (12) when the phase current is flat topped (Wang, 1999).

$$
T_{a v}=\frac{m N_{r} U_{s}^{2}}{2 \pi \omega_{r}^{2}}\left(\theta_{o f f}-\theta_{1}\right)\left[\frac{\theta_{1}-\theta_{o n}}{L_{\min }}-\frac{1}{2} \frac{\theta_{o f f}-\theta_{1}}{L_{\max }-L_{\min }}\right]
$$

where $T_{a v}$ is the average torque, $m$ is the number of motor phase, $N_{r}$ is the number of rotor tooth, $U_{s}$ is the power supply voltage, $\omega_{r}$ is angular speed of the rotor, $\theta_{o n}$ is the angle of starting the excitation, $\theta_{\text {off }}$ is the angle of switching off the excitation, $\theta_{1}$ is the starting angle of the phase inductance increasing, $L_{\max }$ and $L_{\min }$ are the maximum and minimum value of phase inductance, respectively.

Based on (12), the total differential equation of $T_{a v}$ can be written as (He et al., 2004)

$$
d T_{a v}=\frac{\partial T_{a v}}{\partial U_{s}} d U_{s}+\frac{\partial T_{a v}}{\partial \theta_{o n}} d \theta_{o n}+\frac{\partial T_{a v}}{\partial \theta_{o f f}} d \theta_{o f f}+\frac{\partial T_{a v}}{\partial \omega_{r}} d \omega_{r}
$$

According to the linearization theory, the differential of each variable in (13) can be replaced by corresponding increment. If voltage PWM control is adopted, $\theta_{\text {on }}$ and $\theta_{\text {off }}$ are fixed. The simplified small-signal torque equation can be obtained as

$$
\Delta T_{a v}=k_{u} \Delta U_{s}-k_{\omega} \Delta \omega_{r}
$$


The increment of the average torque also can be indicated as

$$
\Delta T_{a v}=J \frac{d \Delta \omega_{r}}{d t}+B \Delta \omega_{r}+\Delta T_{L}
$$

where $J$ is rotary inertia, $B$ is damping coefficient, $T_{L}$ is load torque.

The voltage chopping can be treated as a sampling process of the controller's output $\Delta U_{A S R}$, and the amplification factor is $K_{c}$. The small-signal model of power inverter can be given as

$$
\Delta U_{s}(s)=k_{c} \cdot \frac{1-e^{-T s}}{s} \Delta U_{A S R}(s)=k_{c} \cdot \frac{T}{1+T S} \Delta U_{A S R}(s)
$$

The feedback of angular speed can be treated as a small inertial element.

$$
G_{\omega}(s)=k_{n} /\left(1+T_{\omega} s\right)
$$

where $K_{n}$ is feedback coefficient and $T_{\omega}$ is time constant of the measurement system.

Based on above analysis, the simplified small-signal model of SRM can be got as shown in Fig. 8 .

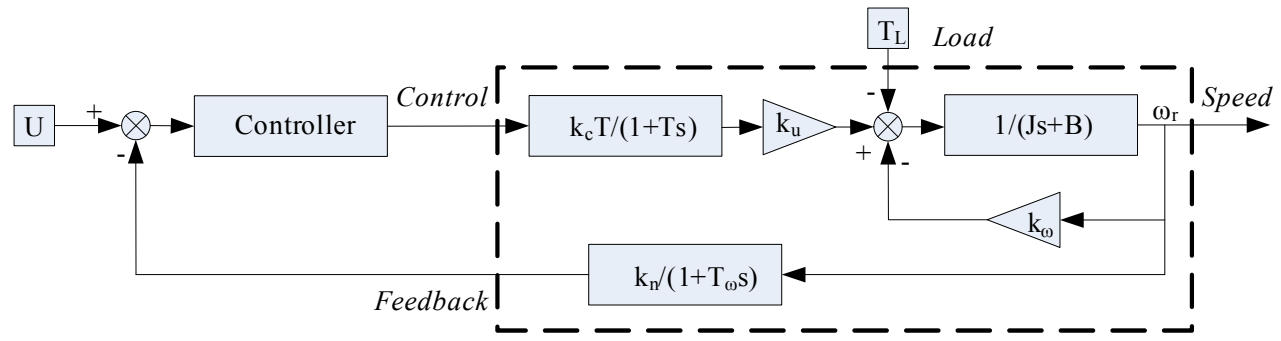

Fig. 8. The simulation model of SRM

\section{Design of I-PID Controller}

\subsection{FPID Controller for SRM}

Based on Fig.1, Fig. 4 and Fig. 8, the simulation model of C-PID and FPID for SRM can be obtained as shown in Fig. 9 and Fig. 10. The internal structure of the module marked "SRM" is the part that enclosed by dashed box in Fig. 8 .

It can be found that the three parameters of the PID controller in FPID control can be obtained by

$$
\left\{\begin{array}{l}
K_{p}=K_{p 0}+\Delta K_{p} \\
K_{i}=K_{i 0}+\Delta K_{i} \\
K_{d}=K_{d 0}+\Delta K_{d}
\end{array}\right.
$$


Where $K_{p 0}, K_{i 0}$ and $K_{d 0}$ are the initial PID parameters obtained by NCD or GA. $\Delta K_{p}, \Delta K_{i}$ and $\Delta K_{d}$ are provided by FLC. They are used to adjust the three parameters online. In other words, the parameters of C-PID can be dynamically tuned by FLC according to different operation conditions. Fig. 11 shows the structure of the FLC used in FPID controller. It has two input variables and three output variables.

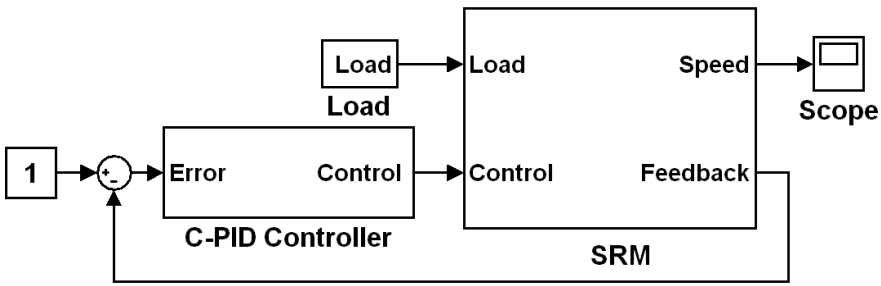

Fig. 9. The simulation model of C-PID controlled SRM system

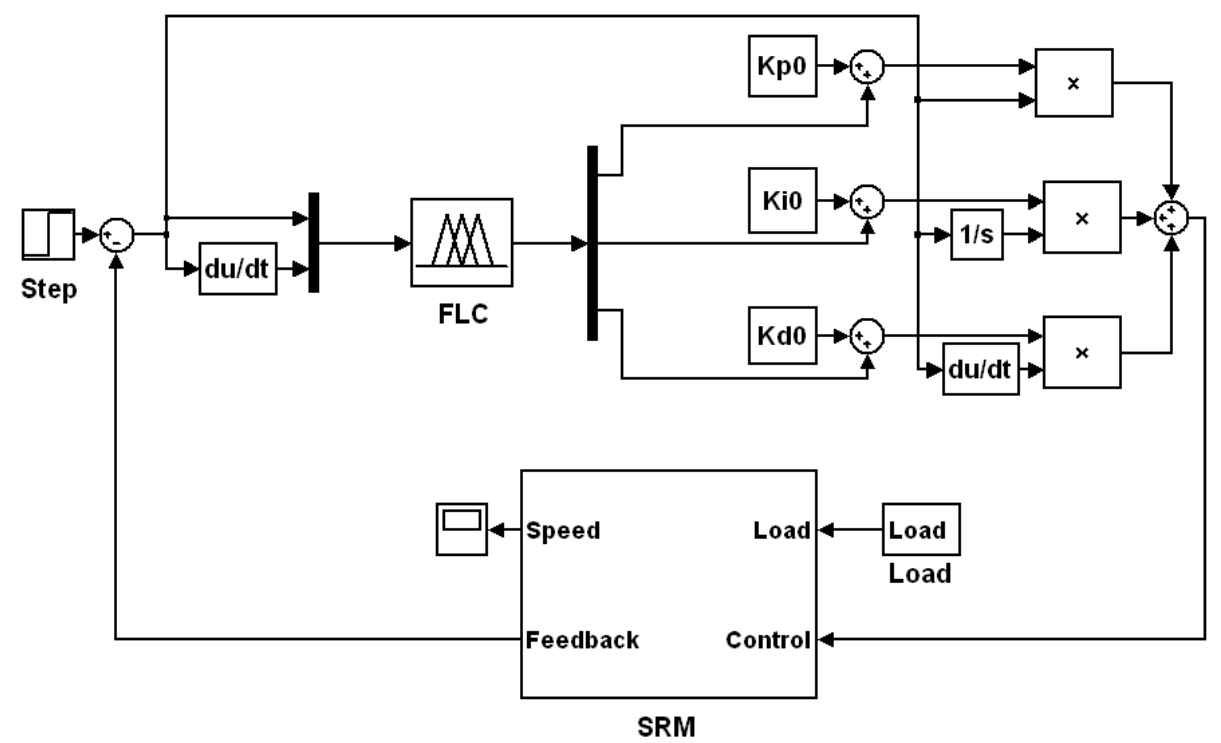

Fig. 10. The simulation model of FPID controlled SRM system

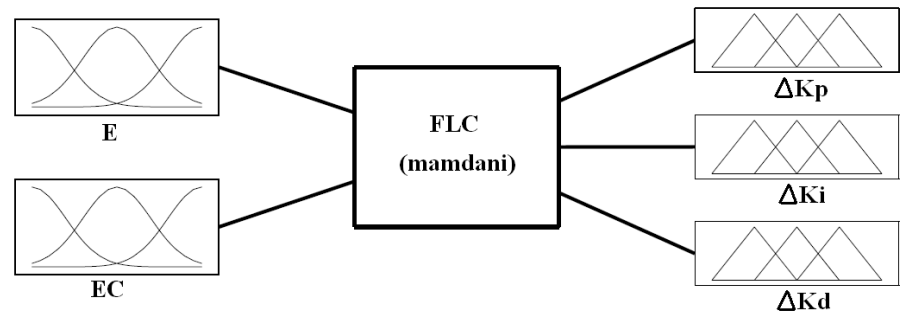

Fig. 11. Structure of the designed FLC used in FPID controller 
The most important thing for the design of FPID controller is the determination of the fuzzy rule base. According to the functions of each PID parameter mentioned in section 2, the principles for their adjustment can be summarized as follows (Shi \& Hao, 2008):

(1) When the absolute value of the system error, $|\mathrm{e}(\mathrm{t})|$, is relatively big: $K_{p}$ is increased to get faster tracking speed, $K_{i}$ is reduced to avoid overshoot.

(2) When $|\mathrm{e}(\mathrm{t})|$ is relatively small: $K_{p}$ and $K_{i}$ are increased to enhance the tracking precision, $K_{d}$ should be proper to avoid steady-state oscillation.

(3) When $|\mathrm{e}(\mathrm{t})|$ is medium: $K_{p}$ is reduced to avoid overshoot, $K_{i}$ is increased slightly to enhance the steady-state precision, and $K_{d}$ should be proper to guarantee the stability of the system.

Based on above principles and consider the change rate of the system error, ec(t), the fuzzy rule base of the three parameters can be obtained. As an example, Table.1 shows the fuzzy rule base for $\Delta K_{p}$.

\begin{tabular}{|c|c|c|c|c|c|c|c|}
\hline & NB & $\mathrm{NM}$ & NS & $\mathrm{ZO}$ & PS & PM & PB \\
\hline NB & NB & NB & NM & PB & $\mathrm{PB}$ & $\mathrm{PB}$ & $\mathrm{ZO}$ \\
\hline $\mathrm{NM}$ & NB & NB & $\mathrm{NM}$ & $\mathrm{PM}$ & $\mathrm{PB}$ & $\mathrm{ZO}$ & PS \\
\hline NS & NB & $\mathrm{NM}$ & NS & PS & $\mathrm{ZO}$ & $\mathrm{NM}$ & NS \\
\hline $\mathrm{ZO}$ & NB & NM & NS & $\mathrm{ZO}$ & NS & $\mathrm{NM}$ & NB \\
\hline PS & NS & NM & $\mathrm{ZO}$ & PS & NS & $\mathrm{NM}$ & NB \\
\hline PM & PS & $\mathrm{ZO}$ & $\mathrm{PB}$ & PM & NM & NB & NB \\
\hline $\mathrm{PB}$ & $\mathrm{ZO}$ & PB & $\mathrm{PB}$ & $\mathrm{PB}$ & NM & NB & NB \\
\hline
\end{tabular}

Table 1. Fuzzy rule base of $\Delta K_{p}$

It can be seen that there are totally 49 fuzzy rules and they are represented by fuzzy linguistic terms, such as if $\mathrm{e}=\mathrm{NB}$ and $\mathrm{ec}=\mathrm{NB}$ then $\Delta K_{p}=\mathrm{NB}, \Delta K_{i}=\mathrm{NB}, \Delta K_{d}=\mathrm{PB}$.

In this chapter, all the variables are described by seven linguistic terms. They are negative big (NB), negative middle (NM), negative small (NS), zero (ZO), positive small (PS), positive middle (PM) and positive big (PB). The universe of input variables, e and ec, is $\{-3-2-1012$

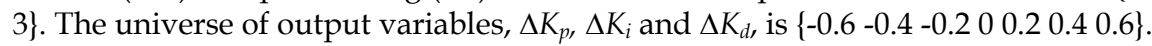

Fig. 12 and 13 show the membership function of each variable.

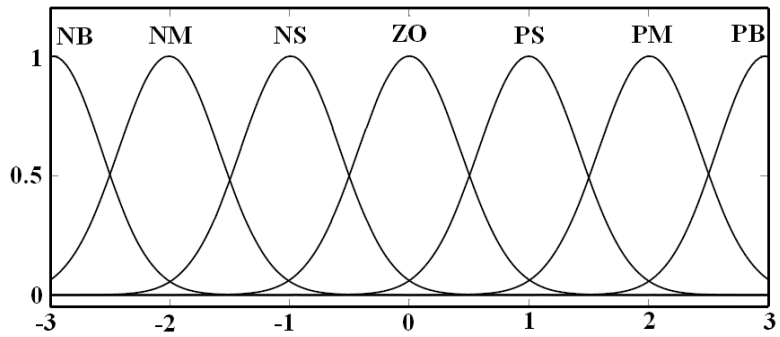

Fig. 12. Membership function of e and ec 


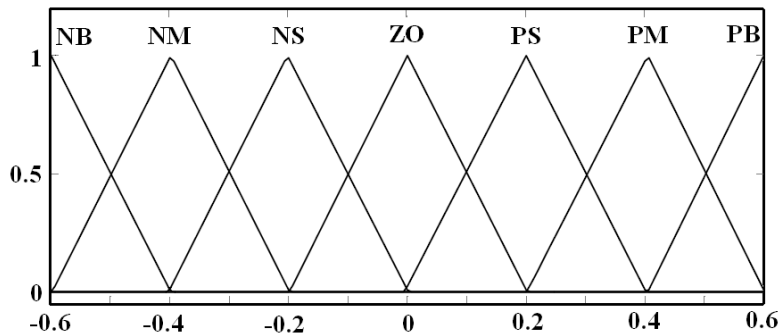

Fig. 13. Membership function of $\Delta K_{p}, \Delta K_{i}$ and $\Delta K_{d}$

In this chapter, the MAX-MIN method is used for fuzzy inference and centroid is used for defuzzification.

\subsection{NNPID Controller for BLDCM}

Based on Fig.1 and Fig. 7, the simulation model of C-PID for BLDCM can be obtained as shown in Fig. 14. The internal structure of the module marked "BLDCM" is the part that enclosed by dashed box in Fig. 7 .

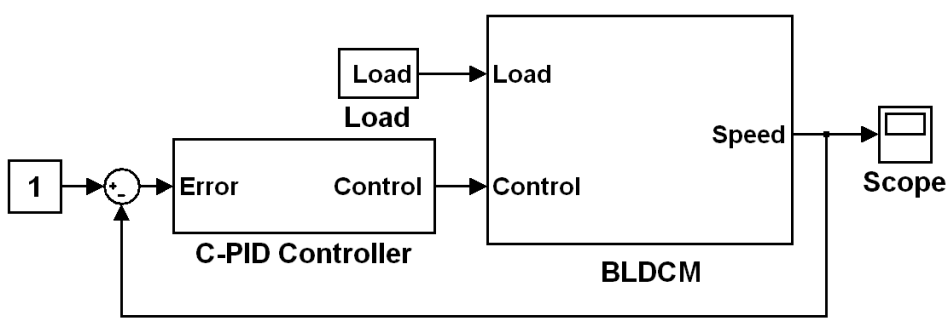

Fig. 14. The simulation model of C-PID controlled BLDCM system

Based on Fig.5 and Fig. 6, the structure of the BPNN used in the NNPID controller is shown in Fig.15.

\section{Hidden layer}

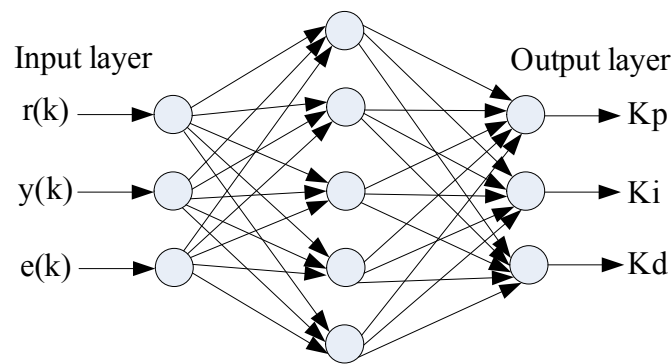

Fig. 15. The structure of the BPNN used in NNPID controller

It can be seen that the adopted BPNN has three layers: one input layer, one hidden layer and one output layer. There are three input variables and three output variables. $r(k)$ is the 
reference input of the system, $y(k)$ is the real output of the system and $e(k)$ is the error between them. $\mathrm{K}_{\mathrm{p}}, \mathrm{K}_{\mathrm{i}}$ and $\mathrm{K}_{\mathrm{d}}$ are the three parameters of the C-PID controller. There are five nodes (neurones) in the hidden layer.

During operation, the connection strength (weights) between neurons can be adjusted automatically through learning based on the input information. The three output variables of NN, $K_{p}, K_{i}$ and $K_{d}$, will be changed along with the adjustment of the connection weights. Finally, the performance of the system can be improved.

The output of nodes in input layer equals to their input. The input and output of nodes in hidden layer and output layer can be represented as (Liu, 2003)

$$
\begin{aligned}
& \text { Hidden }\left\{\begin{array}{l}
\operatorname{in}_{i}^{(2)}(k)=\sum_{j=1}^{3} w_{i j}^{(2)} \text { out }_{j}^{(1)}(k) \\
\text { out }_{i}^{(2)}(k)=f\left[\text { in }_{i}^{(2)}(k)\right]
\end{array} \quad i=1,2,3,4,5\right. \\
& \text { Output }\left\{\begin{array}{l}
\text { in }_{l}^{(3)}(k)=\sum_{i=1}^{5} w_{l i}^{(3)} \text { out }_{i}^{(1)}(k) \\
\text { out }_{l}^{(3)}(k)=g\left[\ln _{l}^{(3)}(k)\right]
\end{array} \quad l=1,2,3\right.
\end{aligned}
$$

where $w_{i j}^{(2)}$ is connection weight between input and hidden layer, $w_{l i}^{(3)}$ is connection weight between hidden and output layer, $f[\cdot]$ and $g[\cdot]$ are activation functions. In this chapter, the activation function of hidden layer is sigmoid function. Because the output variables of NN, $\mathrm{K}_{\mathrm{p}}, \mathrm{K}_{\mathrm{i}}$ and $\mathrm{K}_{\mathrm{d}}$, can't be negative, the activation function of output layer is nonnegative sigmoid function, that is

$$
\left\{\begin{array}{l}
f[x]=\tanh (x)=\frac{e^{x}-e^{-x}}{e^{x}+e^{-x}} \\
g[x]=\frac{(1+\tanh (x))}{2}=\frac{e^{x}}{e^{x}+e^{-x}}
\end{array}\right.
$$

In this chapter, the output variables of NN are the three parameters of C-PID controller, that is

$$
\left\{\begin{array}{l}
\text { out }_{1}^{(3)}(k)=K_{p} \\
\text { out }_{2}^{(3)}(k)=K_{i} \\
\text { out }_{3}^{(3)}(k)=K_{d}
\end{array}\right.
$$

With (19) (22), NN completes the feedforward of the information. The output of the C-PID controller can be got easily based on the three updated parameters, and then the output of the system, $\mathrm{y}(\mathrm{k})$, can be obtained. The next step is the backpropagation of the error.

To minimize the error between $\mathrm{y}(\mathrm{k})$ and $\mathrm{r}(\mathrm{k})$, a performance index function is introduced as 


$$
J(k)=\frac{1}{2}(r(k)-y(k))^{2}=\frac{1}{2} e(k)^{2}
$$

Typically, the connection weights are adjusted by steepest descent method. To increase the convergence speed, an inertia term is added.

$$
\Delta w_{l i}^{(3)}(k)=-\eta \frac{\partial J(k)}{\partial w_{l i}^{(3)}}+\alpha \Delta w_{l i}^{(3)}(k-1)
$$

where $\eta$ is learning rate, is inertia coefficient. In this chapter, $\eta=0.001$ and $\alpha=0.05$.

Based on (19) (24), the connection weights can be tuned dynamically. In this chapter, the NNPID controller for BLDCM is implemented by M-File in Matlab.

\section{Performance Verification}

\subsection{FPID Controller for SRM}

In this chapter, the parameter values of the SRM (see Fig. 8) are as follows:

$\mathrm{k}_{\mathrm{c}}=45, \mathrm{~T}=0.5 \mathrm{~ms}, \mathrm{k}_{\mathrm{u}}=22.45, \mathrm{~J}=1 \mathrm{~kg} \cdot \mathrm{m}^{2}, \mathrm{~B}=1, \mathrm{k}_{\mathrm{n}}=1, \mathrm{~T}_{\omega}=1.5 \mathrm{~ms}, \mathrm{k}_{\omega}=0.05$.

The initial values of the three parameters in C-PID are

$\mathrm{K}_{\mathrm{p}}=5, \mathrm{~K}_{\mathrm{i}}=7, \mathrm{~K}_{\mathrm{d}}=2$.

Fig. 16 shows the step response of the SRM with C-PID and FPID controller, respectively. The reference angular speed is 100rad/s. The motor is started without load, and at $10 \mathrm{~s}$ a $50 \mathrm{Nm}$ load is added.

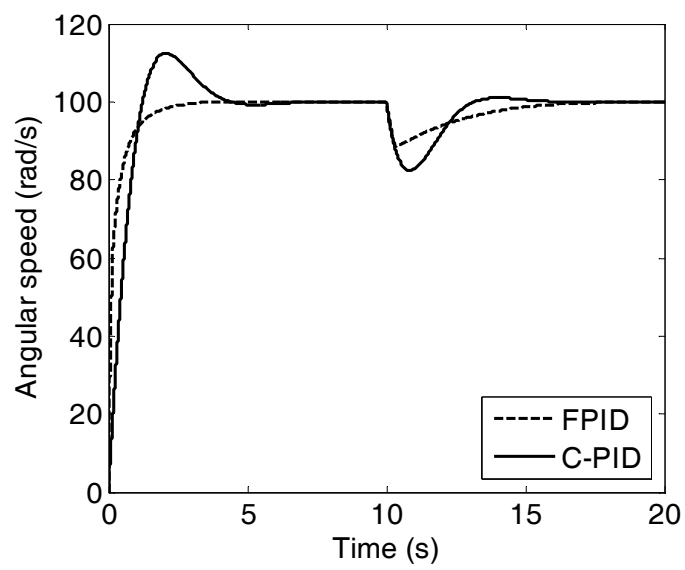

Fig. 16. The step response of the SRM

It can be seen that compared with C-PID controller, the FPID controller can improve the performance of the system significantly. It has advantages of no overshoot, shorter adjusting time. Moreover, when add load torque suddenly at 10s, the drop of the angular speed is smaller and the transition time is shorter. 
Fig. 17 shows the adjustment of the three parameters, $K_{p}, K_{i}$ and $K_{d}$, in FPID controller.

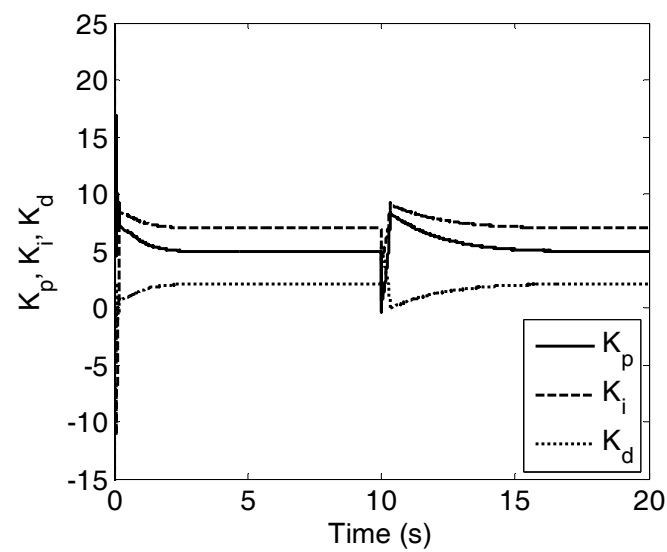

Fig. 17. The adjustment of $K_{p}, K_{i}$ and $K_{d}$ in FPID controller

It can be found that during the adjustment process of the angular speed, the three parameters are tuned dynamically as well. When the system reaches its steady-state, the angular speed is constant and the three parameters are also changed into their initial values.

\subsection{NNPID Controller for BLDCM}

The discrete form of the BLDCM used in this chapter is

$$
y(k)=0.417 * y(k-1)+0.102 * y(k-2)+3.058 * u(k-1)
$$

where $u$ is the output of the C-PID controller.

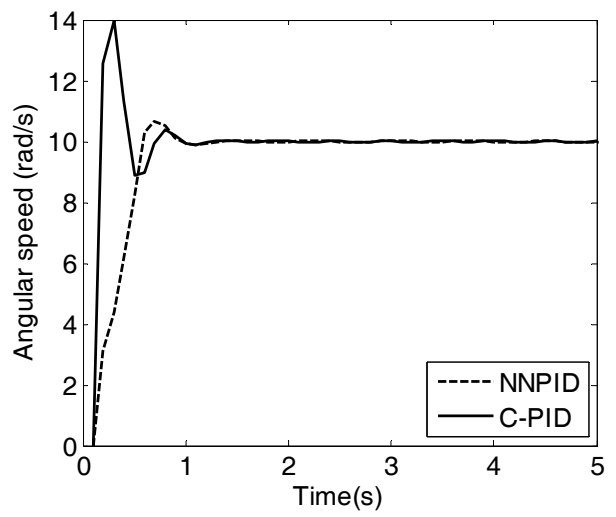

Fig. 18. The step response of the BLDCM 


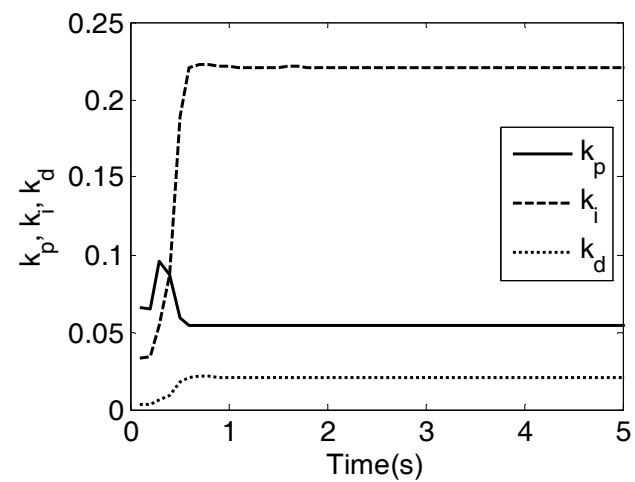

Fig. 19. The adjustment of $K_{p}, K_{i}$ and $K_{d}$ in NNPID controller

Fig. 18 shows the step response of the BLDCM with C-PID and NNPID controller, respectively. The reference angular speed is 10 rad/s. The motor is started without load.

It can be seen that compared with C-PID controller, the NNPID controller can improve the performance of the system significantly. The overshoot of the system is nearly eliminated. However, because NNPID controller needs time to train NN, the adjusting times of the system with two controllers are almost the same.

Fig. 19 shows the adjustment of the three parameters, $K_{p}, K_{i}$ and $K_{d}$, in NNPID controller. It can be found that during the adjustment process of the angular speed, the three parameters are tuned dynamically. When the system reaches its steady-state, the angular speed is constant and the three parameters are constant as well.

\section{Conclusion}

In this chapter, the structure and operation principle of C-PID controller are introduced firstly. According to the shortcomings of C-PID controller, two improved PID controllers, namely FPID and NNPID controller, are studied. The structure and operation principle of them are analyzed. Then, the BLDCM and SRM drive system are introduced and their mathematical models are built. Based on the models, FPID and NNPID controller are designed in detail. Finally, the performances of the designed controllers are tested by simulation. The simulation results show that compared with C-PID controller, both FPID and NNPID controller can improve the performance of the system significantly.

\section{References}

Ang K. H.; Chong G. \& Li Y. (2005). PID Control System Analysis, Design, and Technology. IEEE Transactions on Control Systems Technology, Vol.13, No.4, July 2005, 559-576, ISSN 1063-6536.

Li X.; Mao X. \& Lin W. (2010). Permanent Magnet Synchronous Motor Decoupling Control Study Based on the Inverse System, Proceedings of Progress In Electromagnetics Research Symposium, pp. 300-303, ISBN 978-1-934142-14-1, Cambridge, July 2010, Electromagnetics Academy, Cambridge. 
Tang K. S.; Man K. F.; Chen G. \& Kwong S. (2001). An Optimal Fuzzy PID Controller. IEEE Transactions on Industrial Electronics, Vol.48, No.4, August 2001, 757-765, ISSN 02780046.

Yu H.; Zhang X. \& Hu Q. (2009). Application of NN-PID Control in Linear Elevator, Proceedings of Fifth International Conference on Natural Computation, pp. 35-37, ISBN 978-0-7695-3736-8, Tianjian, August 2009, IEEE Computer Society, Los Alamitos.

Lin C.; Jan H. \& Shieh N. (2003). GA-Based Multiobjective PID Control for a Linear Brushless DC Motor. IEEE/ASME Transactions on Mechatronics, Vol.8, No.1, March 2003, 56-65, ISSN 1083-4435.

Chen H. \& Gu J. J. (2010). Implementation of the Three-Phase Switched Reluctance Machine System for Motors and Generators. IEEE/ASME Transactions on Mechatronics, Vol.15, No.3, June 2010, 421-432, ISSN 1083-4435.

Wu H.; Cheng S. \& Cui S. (2005). A Controller of Brushless DC Motor for Electric Vehicle. IEEE Transactions on Magnetics, Vol.41, No.1, January 2005, 509-513, ISSN 0018-9464.

Shi X. \& Hao Z. (2008). Fuzzy Control and Its Simulation in Matlab, Tsinghua University Press, ISBN 978-7-81123-029-1, Beijing.

Wei W. (2004). MATLAB control engineering toolbox technique manual, National Defence Industrial Press, ISBN 7-118-03205-0, Beijing.

Qin G.; Yao W. \& Zhang W. (2005). Design of Nonlinear Optimization PID Controller for BLDCM Based on Neuro-Fuzzy Identified Model, Proceedings of the Eighth International Conference on Electrical Machines and Systems, pp. 1524-1527, ISBN 75062-7407-8, Nanjing, September 2005, Beijing World Publishing Corporation, Beijing.

Naayagi R. T. \& Kamaraj V. (2005). Shape Optimization of Switched Reluctance Machine for Aerospace Applications, Proceedings of 31st Annual Conference of IEEE Industrial Electronics Society, pp. 1748-1751, ISBN 0-7803-9252-3, Raleigh, November 2005, IEEE Industrial Electronics Society, Los Alamitos.

Vasconcelos J. A.; Ramirez J. A.; Takahashi R. H. C. \& Saldanha R. R. (2001). Improvements in Genetic Algorithms. IEEE Transactions on Magnetics, Vol.37, No.5, September 2001, 3414-3417, ISSN 0018-9464.

Xu J.; Zhao J.; Luo L. \& Wan S. (2004). Expert PID Control for AC/DC Converter, Proceedings of The Fifth World Congress on Intelligent Control and Automation, pp. 5586-5590, ISBN 0-7803-8273-0, Hangzhou, June 2004, IEEE Industrial Electronics Chapter, Singapore.

Liu X. \& Li X. (2010). Research on Tension Control System Based on Fuzzy Self-tuning PID Control, Proceedings of 2010 Chinese Control and Decision Conference, pp. 3385-3390, ISBN 978-1-4244-5182-1, Xuzhou, May 2010, IEEE Industrial Electronics Chapter, Singapore.

Liu W. \& Song S. (2006). Application of Fuzzy Control in Switched Reluctance Motor Speed Regulating System, Proceedings of International Conference on Computational Intelligence for Modelling, Control and Automation, pp. 72-72, ISBN 0-7695-2731-0, Sydney, November 2006, Patrick Kellenberger, Sydney.

Tao Y. (2002). Novel PID Control and Its Application, China Machine Press, ISBN 7-111-06299$X$, Beijing.

Liu J. (2003). Novel PID Control and Its Simulation in Matlab, Publishing House of Electronic Industry, ISBN 7-5053-8427-9, Beijing. 
Wang J.; Zhang C.; Jing Y. \& An D. (2007). Study of Neural Network PID Control in Variable-frequency Air-conditioning System, Proceedings of IEEE International Conference on Control and Automation, pp. 317-322, ISBN 1-4244-0818-0, Guangzhou, May 2007, IEEE Control Systems Chapter, Singapore.

Wang H. (1999). Switched Reluctance Motor Speed Adjusting System, China Machine Press, ISBN 7111-04623-4, Beijing.

He L.; Wan P. \& Xiao H. (2004). Application of PID-Fuzzy Controller in Switched Reluctance Motor Drives. Middle and Small Motor, Vol.31, No.4, August 2004, 32-35, ISSN 10018085 . 


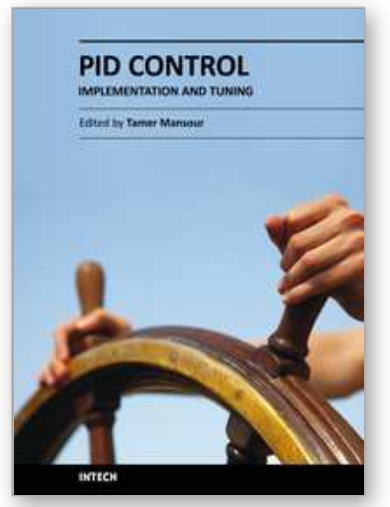

\author{
PID Control, Implementation and Tuning \\ Edited by Dr. Tamer Mansour
}

ISBN 978-953-307-166-4

Hard cover, 238 pages

Publisher InTech

Published online 19, April, 2011

Published in print edition April, 2011

The PID controller is considered the most widely used controller. It has numerous applications varying from industrial to home appliances. This book is an outcome of contributions and inspirations from many researchers in the field of PID control. The book consists of two parts; the first is related to the implementation of PID control in various applications whilst the second part concentrates on the tuning of PID control to get best performance. We hope that this book can be a valuable aid for new research in the field of PID control in addition to stimulating the research in the area of PID control toward better utilization in our life.

\title{
How to reference
}

In order to correctly reference this scholarly work, feel free to copy and paste the following:

Song Shoujun and Liu Weiguo (2011). Application of Improved PID Controller in Motor Drive System, PID Control, Implementation and Tuning, Dr. Tamer Mansour (Ed.), ISBN: 978-953-307-166-4, InTech, Available from: http://www.intechopen.com/books/pid-control-implementation-and-tuning/application-of-improved-pidcontroller-in-motor-drive-system

\section{INTECH}

open science | open minds

\section{InTech Europe}

University Campus STeP Ri

Slavka Krautzeka 83/A

51000 Rijeka, Croatia

Phone: +385 (51) 770447

Fax: +385 (51) 686166

www.intechopen.com

\section{InTech China}

Unit 405, Office Block, Hotel Equatorial Shanghai

No.65, Yan An Road (West), Shanghai, 200040, China

中国上海市延安西路65号上海国际贵都大饭店办公楼 405 单元

Phone: +86-21-62489820

Fax: +86-21-62489821 
(C) 2011 The Author(s). Licensee IntechOpen. This chapter is distributed under the terms of the Creative Commons Attribution-NonCommercialShareAlike-3.0 License, which permits use, distribution and reproduction for non-commercial purposes, provided the original is properly cited and derivative works building on this content are distributed under the same license. 